\title{
Teleconnection between Australian winter temperature and Indian summer monsoon rainfall
}

\author{
S.-Y. Lee ${ }^{1}$ and T. Y. Koh ${ }^{1,2}$ \\ ${ }^{1}$ School of Physical and Mathematical Sciences, Nanyang Technological University, Singapore \\ ${ }^{2}$ Earth Observatory of Singapore, Nanyang Technological University, Singapore \\ Correspondence to: T.-Y. Koh (kohty@ntu.edu.sg)
}

Received: 1 July 2011 - Published in Atmos. Chem. Phys. Discuss.: 22 September 2011

Revised: 9 January 2012 - Accepted: 10 January 2012 - Published: 16 January 2012

\begin{abstract}
The pattern of evaporative sources and the direction of the large-scale circulation over the Indian Ocean during the boreal summer raises the question of whether atmospheric conditions in Australia could influence conditions over the Indian subcontinent, despite the long passage of air over the Indian Ocean. The authors propose that such an influence is sometimes possible when there is unusually low temperature over inland Australia during the austral winter, through the mechanism where such a temperature extreme enhances evaporation rate over the eastern tropical Indian Ocean and hence enhances rainfall over two regions in western India after 13-19 days. Results from trajectory calculations indicate that such an influence is mechanistically feasible, with air of Australian origin contributing 0.5-1.5\% of the climatological net precipitation for monsoon seasonal rainfall over western India. Statistics performed on reanalysis, satellite and in situ data are consistent with such a mechanism. Since extreme winter temperature in Australia is often associated with cold-air outbreaks, the described mechanism may be an example of how southern hemispheric midlatitude weather can influence northern hemispheric monsoon rainfall. Further study is recommended through modelling and comparison with various known causes of atmospheric variability to confirm the existence of such a mechanism and determine the extent of its influence during specific low temperature episodes.
\end{abstract}

\section{Introduction}

The Indian summer monsoon displays huge variability with interannual and intraseasonal components, though there are varied opinions on how much of the interannual monsoon variability is the mean expression of intraseasonal variability, and how much of the intraseasonal variability is actually interannual variability. Comparisons of empirical orthogonal functions have yielded different results. Some findings favour intraseasonal dominance (e.g. Goswami and Mohan, 2001; Lawrence and Webster, 2001), others favour interannual dominance (e.g. Singh et al., 1992; Annamalai et al., 1999; Sperber et al., 2000; Krishnamurthy and Shukla, 2000). Although opinions vary on the extent of their influence, it is generally agreed upon that interannual phenomena such as the El Nino-Southern Oscillation (ENSO) (Rasmusson and Carpenter, 1983) and Indian Ocean Dipole (IOD) (Saji et al., 1999) have significant influence on Indian monsoon rainfall. ENSO and IOD are measured by the various Nino indices (see Hanley et al., 2003, for a comparison) and the Dipole Mode Index (DMI) respectively.

The above-mentioned literature focused on tropical climatic patterns. Other studies consider northern hemispheric influences on the monsoon, such as the Eurasian snow cover (Hahn and Shukla, 1976; Kripalani and Kulkarni, 1999; Liu and Yanai, 2002). Less has been said about interaction between the Southern Hemisphere and Indian monsoon. There are works that investigated the reverse influence of monsoon variability in northern Australia, e.g. Matsumoto (1992) and Krishnamurti et al. (1995). The Indian summer monsoon is correlated with the next Australian summer monsoon in both onset date (Joseph et al., 1991) and strength (Gregory, 
1991). Meehl (1987, 1997) explains this relationship as due to the intense convection in a strong Indian monsoon migrating southeast to Australia as the year progresses, producing a strong Australian monsoon. Incidentally, there is no analogous effect of Australian monsoon on the next Indian summer monsoon (Hung et al., 2004).

As for the influence of the Southern Hemisphere on Indian monsoon variability, it is known that the sea surface temperature (SST) near Australia influences Indian monsoon rainfall. The example of SST influence reported in Nicholls (1995) appears to be part of the ENSO/IOD pattern, but Clark et al. (2000) showed that after excluding ENSO influences, the preceding boreal spring SST north of Australia does have a residual impact on Indian monsoon rainfall.

So, not detracting from the important influence of tropical climatic variations like ENSO and IOD, and the influence of austral tropical SST on Indian summer monsoon, this paper aims to show that there may exist a dynamically plausible way for Australian weather to influence Indian summer monsoon. If so, further investigation into this possibility would be warranted.

\section{Motivation}

The tropical Indian Ocean is known to be a major source of the water vapour arriving on the Indian Subcontinent during the boreal summer (e.g. Gimeno et al., 2010; Stohl and James, 2005). The shape of the evaporative pattern over the Indian Ocean, which appears to follow the large-scale clockwise circulation around the Indian Ocean, suggests the question of whether atmospheric conditions in Australia can influence those over the Indian subcontinent.

Since a non-negligible source of moisture in this system lies just off the coast of Australia, the temperature and humidity of air parcels entering the large scale circulation from Australia would affect the evaporative flux in this region. This suggests the question of whether meteorological conditions over Australia can result in variability in this regional evaporative flux and subsequently affect precipitation in India.

There are two major caveats that must be addressed before such an influence can even be considered. Firstly, whether the amount of water vapour provided by the air originating from Australia (if any) is large enough, relative to the amount provided by air not of Australian origin, that its variability is detectable. Secondly, whether the air parcel can retain the influences of its Australian origin until India, despite the long passage of air over the Indian Ocean.

With these caveats in mind, we hypothesise the existence of a different type of teleconnection between Australia and India that does not arise through simultaneous driving by an external variability (e.g. ENSO or IOD): if the originating conditions are extremely cold and hence dry over interior Australia during austral winter, the rainfall in the same-season Indian monsoon is enhanced via increase in evaporation over eastern tropical Indian Ocean (henceforth "Australia-Indian teleconnection"). If there is such an influence, it should be present only in regions of India where air parcels originating from Australia pass over the Indian Ocean and directly offload their moisture content onto India. Backtrajectory calculations will be employed to test the mechanistic realism of such the hypothetical mechanism. Reanalysis, satellite and in-situ data will be examined for consistency with the hypothesis.

\subsection{Organisation}

This paper is organised as follows: Sect. 3 provides the details of the data and methods adopted in this research, leaving Sect. 4 to focus on the main results and their interpretation. The key conclusions are stated in Sect. 5 .

\section{Data and methodology}

\subsection{Back-trajectory calculations}

Back-trajectories are calculated for up to 30 days using 6hourly winds from the NCEP/ NCAR Reanalysis 1 (henceforth "NNRP", Kalnay et al., 1996, download url listed under NNRP (2012) in the Bibliography) at horizontal resolution $2.5^{\circ} \times 2.5^{\circ}$ and 12 pressure levels $(1000,925,850,700,600$, $500,400,300,250,200,150$, and $100 \mathrm{mb}$ ), using the trajectory algorithm and code of Barras and Simmonds (2009). Air parcels are initialised over land regions of the Indian subcontinent at horizontal resolution of $0.25^{\circ} \times 0.25^{\circ}$ apart, to match the Tropical Rain Measuring Mission (TRMM) resolution used later, and on 8 pressure levels $(1000,925,850$, $700,600,500,400$, and 300 millibars), for a total of 38592 parcels per timestep or 4824 parcels per level. Parcels are not initialised on the remaining 4 pressure levels ( 250 to 100 millibars). This is because no humidity data is available for pressure levels higher than $300 \mathrm{mb}$, and humidity is assumed to be effectively zero above this level. While it is possible that an air parcel on these levels can reach Australia in a backtrajectory calculation, it must have passed the $300 \mathrm{mb}$ pressure level before reaching India, at which time all moisture is assumed to have been removed from the air parcel. Calculations are started once a week in July and August, for a total of 9 weeks, to sample 30-day trajectories that travel through the Indian Ocean during austral winter, for the years 19722008. This provides a statistically representative number of sampled days, while keeping the experiment computationally feasible. From a theoretical viewpoint, such a weekly initialisation is acceptable because the timescale of the phenomena in question is between 2 to 3 weeks as will be seen later (also, from preliminary calculations). However, calculations are started at all 4 timesteps of the sampled day to sample diurnal changes in wind, since the scale of diurnal 
variation can be large compared to day-to-day changes, especially at coastal regions. Air parcel positions are collected once every $6 \mathrm{~h}$.

Back-trajectories that do not reach Australia, defined as entering the region $\left(115-150^{\circ} \mathrm{E}, 15-30^{\circ} \mathrm{S}\right)$, are excluded. There are many back-trajectories that pass over the Indian Ocean but only air parcels that reach India from Australia are of interest, as well as the climatological pattern of their accumulated water-vapour change $(\overline{p-e}$, the climatology difference between accumulated precipitation $p$ and evaporation e).

The net precipitation and net evaporation sections are calculated along all of the remaining back-trajectories using a method modified from Stohl and James (2004). For each particle of mass $m$, the change in water vapour content $m \delta q / \delta t$ depends on its change in specific humidity $\delta q$, at $\delta t 6$ hourly intervals. At any time, particles are collected over a horizontal grid of resolution $0.25^{\circ} \times 0.25^{\circ}$, to match TRMM resolution. For each atmospheric column, the change in water vapour content of a section of the column can be obtained by amassing changes of water vapour content of all particles representative of that section, $\Sigma_{i}^{n} m \delta q_{i} / \delta t=\left(g^{-1} \delta p / \delta t\right) \Sigma_{i}^{n} \delta q_{i}$, where $g$ is the gravitational acceleration and $\delta p$ is the pressure thickness of the air parcel. Hence, the accumulated change in water vapour for the entire column can be obtained by summing all changes in water vapour content in the column, $\Sigma_{j}\left(g^{-1} / \delta t\right) \delta p_{j} \Sigma_{i}^{n(j)} \delta q_{i}$ which henceforth will be termed net precipitation if $p-e$ is positive, and net evaporation $p-e$ is negative. The accuracy of this method does depend on having a representatively large enough number of particles or trajectories. Fortunately, as shall be seen later, the particles in question tend to be concentrated along one particular pathway, and accumulation through $37 \mathrm{yr}$ or 1332 timesteps should be sufficient to obtain a reasonably accurate pattern of $\overline{p-e}$.

Since the mechanism specifically involves evaporation over the eastern Indian Ocean and precipitation over India, it is desirable to refine the net quantities further to distinguish between evaporation and precipitation. This is feasible for evaporation over the Ocean and the method of Sodemann et al. (2008) is employed wherein only net evaporation changes that take place within the atmospheric boundary layer are collected. We wish to establish a lower bound for the amount of evaporation into these air parcels over the main water vapour source of Indian Ocean, to determine how much water vapour at least is entering air parcels from Australia to India. Therefore unlike Sodemann, who calculated the boundary layer height using the methodology of Troen and Mahrt (1986), a boundary layer height is chosen to represent a daytime lower limit, and only negative changes in water vapour along the back-trajectory (i.e. $p-e<0$ ) that occur below this limit are considered evaporation, with evaporation during the day expected to dominate that during the night. Troen models the boundary layer height for 16 and 17
August over Wangara, Australia (Clarke et al., 1971). Using their results as a basis, for the same season, similar latitude, and full moisture availability over the ocean, the daytime lower limit of $1000 \mathrm{~m}$ is chosen for our calculation.

It is however not feasible to obtain the predominating quantity $p$ from $p-e$ for the mechanism and region in question. Not only is it difficult ascertain the location of precipitation using model variables such as relative humidity, since the humidity over the tropical Indian Ocean and at the coasts of India is high, but it is difficult to difficult to dissociate precipitation from evaporation in this situation as well, since Indian monsoon rainfall is intense (e.g. in the Goa station, more than 10 inches can fall in a day, for consecutive days). During such intense rainfall, the ground is saturated with water or flooded, and evaporation accordingly increases. Therefore, $p-e$ is accumulated unaltered and termed "net precipitation".

Back-trajectories are classified as belonging to the "West India domain" (land regions of $\left(68-78^{\circ} \mathrm{E}, 8-30^{\circ} \mathrm{N}\right)$ ) or the "East India domain" (land regions of $\left(78-93^{\circ} \mathrm{E}, 6-28^{\circ} \mathrm{N}\right)$ ), from whether travelling from Australia to India, the first net precipitation event over India occurs in the West India or East India domain. The East India and West India domains are shown as red boxes in Fig. 1a and $1 \mathrm{~b}$ respectively. Thus, travelling from Australia to India, an air parcel may finally reach East India, but should it reach India through the Arabian Sea branch and precipitate on West India, it is considered to belong to the West India domain. However, should such a parcel not precipitate on West India despite passing through West India, and only precipitate in East India, it is considered to belong to the East India domain. Air parcels that do not precipitate in either West or East India domains are not considered to belong in either domain. West India air parcels that travel into East India are terminated at the first precipitation point after leaving the West India domain. This is done likewise for parcels travelling into West India from East India. This permits evaporation segments along the trajectory inside the domain to be included into the calculation of the accumulated water vapour change and prevents the accumulated water vapour change from being biased towards precipitation at the edges of the domains.

The trajectory times from India to when air parcels first cross the line $\left(110^{\circ} \mathrm{E}, 37.5^{\circ} \mathrm{S}\right)-\left(145^{\circ} \mathrm{E}, 11.25^{\circ} \mathrm{S}\right)$ located in interior Australia are collected. We wish to estimate an upper bound of time-lag between low temperature events in Australia and precipitation events in India. Air parcels are observed from the back-trajectories to circulation inside Australia for a few days before leaving Australia. Since low temperature events in Australia can last a few days, air parcels can leave Australia any time during the event. Trajectory times from when air parcels first cross the line $\left(110^{\circ} \mathrm{E}\right.$, $\left.37.5^{\circ} \mathrm{S}\right)-\left(145^{\circ} \mathrm{E}, 11.25^{\circ} \mathrm{S}\right)$ to when they depart Australia (e.g. to re-enter the Indian Ocean), are also collected. The sum of the two trajectory times, from India to interior Australia, and from interior Australia out of Australia, gives the 

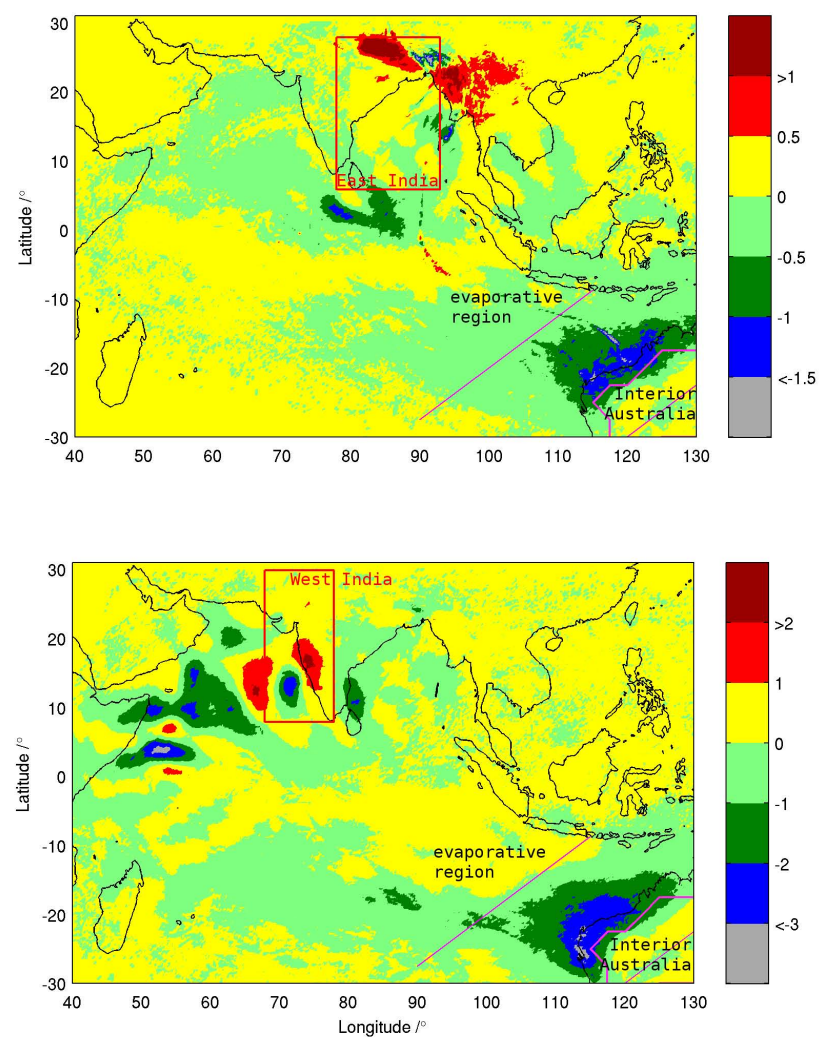

Fig. 1. (a) Climatological accumulated net water vapour sink $\overline{p-e}$ ( $\mathrm{cm} /$ season) calculated from back-trajectories between India and Australia that precipitate first in the East India domain, for years 1972-2008. (b) Same but for the West India domain. Note that the colour scale used for the East India domain is half that used for the West India domain.

desired upper bound estimate. The trajectory times from India to when air parcels first cross the line $\left(90^{\circ} \mathrm{E}, 27.5^{\circ} \mathrm{S}\right)-$ $\left(115^{\circ} \mathrm{E}, 8.75^{\circ} \mathrm{S}\right)$ located in the Indian Ocean are collected as well. This gives an estimate of the time between evaporation from the Indian Ocean and precipitation in India.

\subsection{Satellite rainfall and reanalysis temperature}

If the hypothesis in Sect. 2 is correct, there should be a lagged anti-correlation between the Australian temperature and Indian rainfall. Furthermore, the lag period for maximum anticorrelation should be consistent with the trajectory times obtained from Sect. 3.1.

To estimate Australian winter temperature, the daily mean temperature at 0.995 sigma-level from NNRP is averaged over a polygonal region within $115-105^{\circ} \mathrm{E}, 35-15^{\circ} \mathrm{S}$, shown in Fig. 1a, b as a magenta polygon. This region is where most back-trajectories reaching Australia pass through. The reason for the polygonal shape is to exclude ocean and coastal regions. Highland regions are included but the exclusion of highland regions is also attempted and does not lead to qual- itative differences. The temperature time series is passed through a 8-days-to-2-months Lanczos band-pass filter to exclude synoptic fluctuations and seasonal signature, including harmonics of the seasonal signature (see Appendix A for the reason behind the choice of 8 days for the higher cut-off frequency). This extracts the intraseasonal signature.

Rainfall in India is provided by the Tropical Rain Measuring Mission (TRMM) 3B42 dataset (Simpson et al., 1996, download source listed under TRMM (2012) in the Bibliography) which is calibrated to rain gauges and geostationary observations for years $1998-2008$. The coverage is $8 \times$-daily at $0.25^{\circ} \times 0.25^{\circ}$ resolution. TRMM data is available every $3 \mathrm{~h}$ and but a daily time series is computed for correlation with the daily mean Australian temperature. Each day's rainfall value is the average of all available TRMM data points in a given domain spanning the 8 time slices of that day. A 8-days-to-2-months Lanczos band-pass filter is applied here as well.

Pearson's correlation between the temperature and rainfall time series is calculated for various time lags. Thresholds are imposed at different temperature percentiles to eliminate warmer temperatures and the corresponding lagged rainfall data, since only cold temperature is believed to be related to Indian rainfall.

\subsection{Regression of in-situ data}

While analysed temperature and TRMM rainfall data provide good horizontal coverage, in-situ station and rain gauge measurements provide longer historical records and hence supply supplementary evidence for the Australia-India teleconnection.

At first sight, the mean of Australian station temperature intuitively corresponds to the mean of gridded reanalysis temperature. But it actually does not because of the highly uneven density of stations in Australia. Stations are concentrated in southeast Australia and sparsely distributed over the northwest and interior regions. The Australian Bureau of Meteorology (download source listed under VCD (2012) in the Bibliography) maintains a long yearly record of the number of very cold days in a year averaged over stations (henceforth "VCD"), where a very cold day is one when the maximum day temperature is below $10^{\circ} \mathrm{C}$. When many stations across Australia (especially those in the southeast) record a very cold day, the entire air mass over Australia, including the less and unobserved regions, is likely to be anomalously cold with respect to the local winter climatology. Thus VCD can be used as an in-situ proxy for extreme coldness over the whole of Australia. As winters in Australia are generally mild, it is expected that the number of days counted by the statistic is dominated by days in the Australian winter season. The VCD statistic is available since 1957 but only years coinciding with available rain gauge data (see next paragraph) will be used. The statistic has a mean value of 10.81 days for the years 1957 to present and ranges from 2.2 days to 19.3 
days in a year. Appendix A supports the use of this proxy by comparing VCD and mean Australian winter temperatures by percentile, from NNRP reanalysis data. The use of $10^{\circ} \mathrm{C}$ as a limit for "low temperature" may not be ideal, but from Appendix A it suffices as a gauge of low Australian winter temperature; other definitions of low Australian temperature should not be remotely different from what is shown by VCD or percentile cold reanalysis temperature in Sect. 4.

The daily accumulated in-situ rainfall comes from individual rain gauges in the National Oceanic and Atmospheric Administration (NOAA) archive. The period of 1977-2008 is selected to obtain the largest number of gauges for a continuous period longer than $30 \mathrm{yr}$, and with at least 26 out of the 32 summer seasons each, or $80 \%$ of the 32 seasons, having at least 30 days of data. Such selection criteria for the gauges ensures that the seasonal mean rainfall obtained is representative. The rain gauge data is not time-filtered to avoid the need to estimate missing data which may produce spurious oscillations of the timescales in question and therefore degrade the value of in-situ measurements.

The mean rainfall from 15 June to 14 September (i.e. JJA lagged by 14 days for the approximate travel time of air parcels, for reasons given later) is calculated every year and correlated against VCD. Although the monsoon season extends beyond this time period, the length of the temperate winter season limits the time period to be considered.

\subsection{Comparison with climatic indices}

It is possible that interannual variations in VCD are related to interannual climatic patterns like ENSO and IOD. This means that any correlation between Indian rainfall and VCD could be due to the dependence on ENSO and IOD phases and should be investigated.

The DMI used to denote the phase of IOD is obtained from Japan Agency for Marine-Earth Science and Technology (JAMSTEC); Nino3 and Nino3.4 indices for denoting the phase of ENSO are from NOAA. VCD is correlated with the mean DMI of August, September and October (ASO) and with the mean Nino3.4 and Nino4 indices of December, January and February (DJF). These are separately the months when IOD and ENSO SST anomalies are usually the largest, and ensures that IOD or ENSO events can be captured even if the respective indices at JJA do not indicate developing events yet. Since ENSO spans more than one year, both VCD from the same (ENSO-developing) and from the following (ENSO-mature) year to the December month in the Nino indices are used.

\subsection{Sea surface evaporation data}

In the course of exploring the mechanism underlying the Australia-India teleconnection, evaporation from Indian Ocean and associated factors are investigated. Monthly mean evaporation rate, specific humidity at $2 \mathrm{~m}$ and SST over the ocean at $1^{\circ} \times 1^{\circ}$ resolution are taken from the Objectively Analyzed Air-Sea Fluxes dataset (OAFlux) of Woods Hole Oceanographic Institution (Yu et al., 2007, download source listed under OAFlux (2012) in the Bibliography). Since only wind magnitudes but not wind vectorial components are available in OAFlux, NNRP $10 \mathrm{~m}$-wind is used instead. Although this wind field is not the same as that used to calculate the evaporation rate in OAFlux, it is one of the inputs used to estimate the OAFlux wind and so is expected to be similar. JJA mean anomalies are computed from 1958-2008 JJA climatology.

\section{Results and discussion}

\subsection{Back-trajectories from India to Australia}

The climatology of the accumulated net precipitation associated with the air parcels of East and West India domain is concentrated in four regions, two in the East India domain and two in the West India domain (Fig. 1a, b, Fig. 5 for India in greater detail).

Figure 1a shows the climatology of the accumulated net water vapour sink, $\overline{p-e}$, for the air parcels originating in Australia with its first accumulated net precipitation in the East India domain. Air parcels approach the Indian Subcontinent from the Bay of Bengal and net precipitation occurs over Northeast India and the Ganges basin. Bangladesh is seen as a net evaporative region, indicating that air parcels from Australia do not contribute to the precipitation in Bangladesh.

Figure $1 \mathrm{~b}$ shows the same, but for the West India domain. Net precipitation occurs on the slopes of the Western Ghats and over Northwest India (Fig. 5). Net precipitation and net evaporation also occur along the stationary waves off the Western Ghats, over the Arabian Sea. The main evaporative source for air parcels of both domains is however the Indian Ocean; net evaporation is seen along most of the backtrajectory pathway in the Indian Ocean. For air parcels originating in Australia, net evaporation is particularly concentrated in the tropical east Indian Ocean, west of Australia.

Of the total air parcels initiated, $3.5 \%$ reach Australia. $3.0 \%$ of these air parcels produce net precipitation in India, while the other $0.5 \%$ produce net precipitation over Indochina. $2.4 \%$ of the total air parcels that reach India are classified as belonging to the West India domain and $0.6 \%$ are classified as belonging to the East India domain.

Assuming that the sampled air parcels are representative of the boreal summer (austral winter) season, seasonal net precipitation from the parcels in question can be estimated by scaling the climatology of net precipitation accumulated over 9 days over the JJA season, by 92 days of the entire JJA season. The contribution to JJA seasonal precipitation by air parcels originating in Australia can reach up to $3 \mathrm{~cm} / \mathrm{JJA}$ season in some regions in West India. The regions where Australian contribution is highest (1-3 cm/JJA season in Fig. 5) 

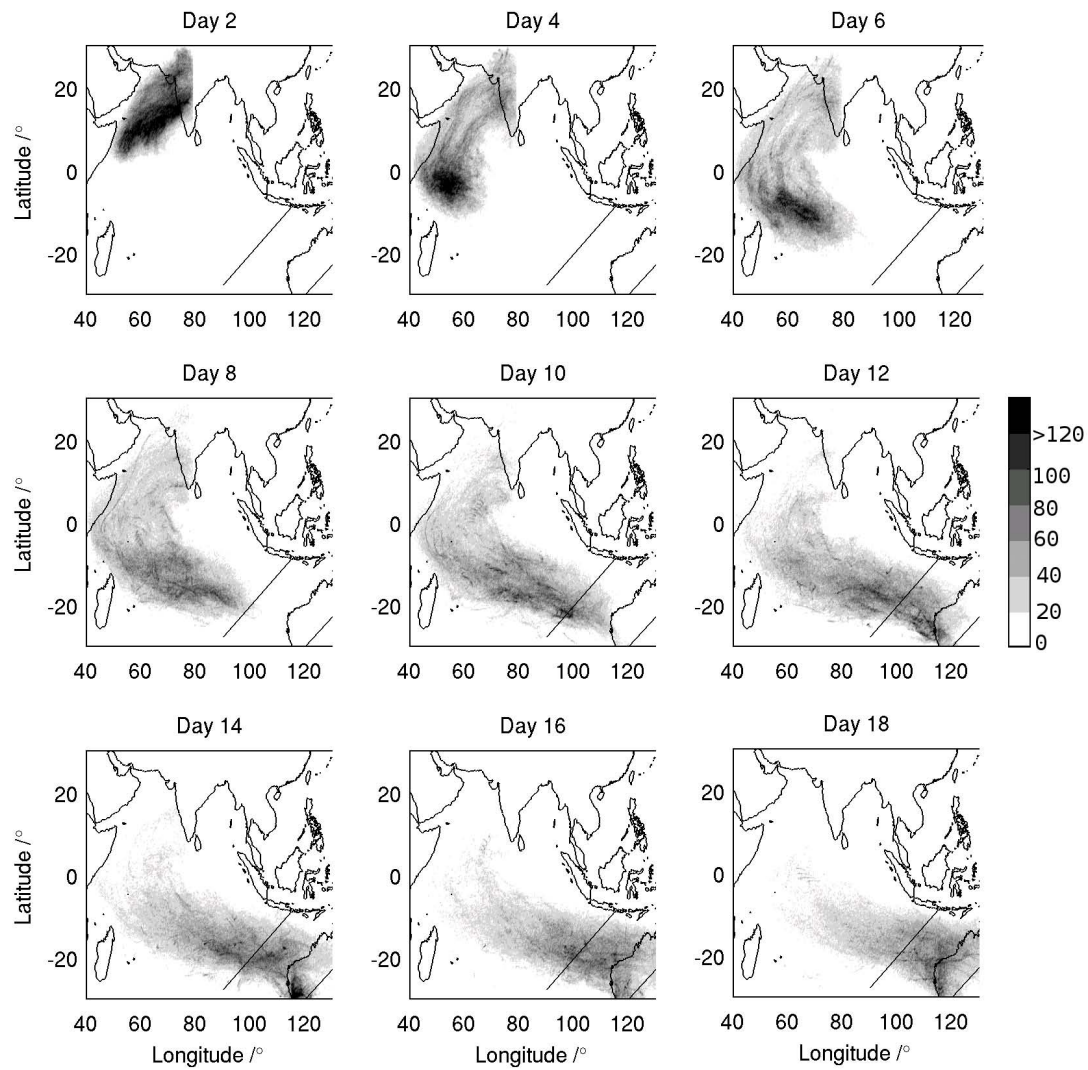

Fig. 2. Shading shows the number density of air parcels at a particular timestep, or the number of air parcels on a $0.25^{\circ} \times 0.25^{\circ}$ resolution grid. Only air parcels of back-trajectories from India that reach Australia and precipitate first in the West India domain are shown. Lines demarcate boundaries of the evaporative region in the tropical east Indian Ocean and of interior Australia. Parcels are removed when they cross the Australian line.

are coincidentally also regions with the highest precipitation of 250-350 cm/JJAS season (see Parthasarathy and Mooley, 1978 , or the most up-to-date rainfall maps at the Indian Meteorological Department website listed under IMD (2012) in the Bibliography). Air with an Australian origin therefore provides approximately $0.5-1.5 \%$ of total seasonal precipitation in West India. This climatological amount is small, but it is not evenly distributed temporally and spatially, ranging from negligible contributions to $10 \mathrm{~cm} / \mathrm{JJA}$ season in regions of West India. However, it must be cautioned that extreme cases such as $10 \mathrm{~cm} / \mathrm{JJA}$ season may be deceptive since Indian monsoonal rainfall itself is highly variable. The Australian contribution to precipitation of particular years must be ascertained through case studies.

These results answer the first caveat raised in Sect. 2. The amount of net precipitation over West India contributed by air parcels Australian in origin is small, but not negligible. Whether this small contribution to the West Indian rainfall can be actually detected on a year-to-year basis will be examined in Sects. 4.2 and 4.3. Much less precipitation over East India can be attributed to air parcels of Australian origin, and the possibility of any Australian influence on East India precipitation is minute.
The second caveat is now addressed.

Figure 2a-i shows the number density of West India air parcels as they travel along the back-trajectory from the Indian end. The number density is the the number of air parcels on a $0.25^{\circ} \times 0.25^{\circ}$ resolution grid at a snapshot in time, with day 0 as the time when the air parcels are at their Indian end of the back-trajectory. Parcels are removed when they cross the line in interior Australia. Air parcels begin to reach the main evaporative region at day 7 . By day 13 , most of the parcels have entered or passed the evaporative region.

The distribution of trajectory times from India to the evaporative region as demarcated by the upper line in Fig. $2 \mathrm{a}-\mathrm{i}$ is shown as pale bars in Fig. 3a-c, for both domains, East India domain, and West India domain. West India air parcels take about 8-13 days to enter the evaporative sink, while East India air parcels take about 13-18 days. Considering that the average residence time of moisture in the atmosphere is about 10 days (Numaguti, 1999), precipitation in East India is not expected to have any relationship with low temperatures in Australia, since any water vapour entering the atmosphere from the evaporative region would have precipitated out by then. Since the trajectory times between West India and the evaporative region are consistent with the known 


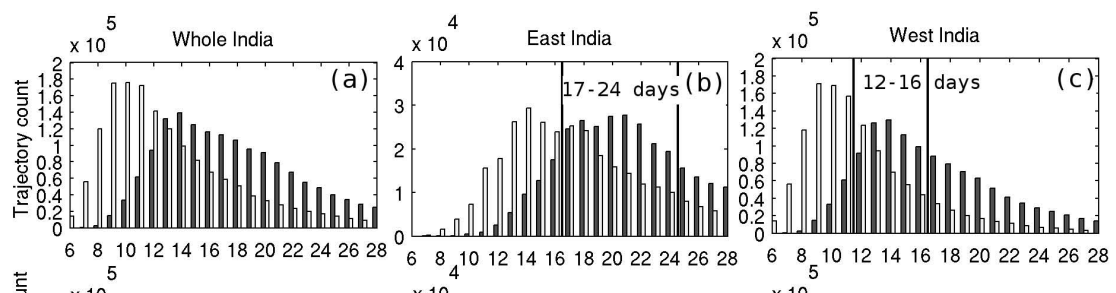

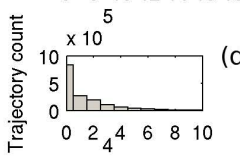

(d)
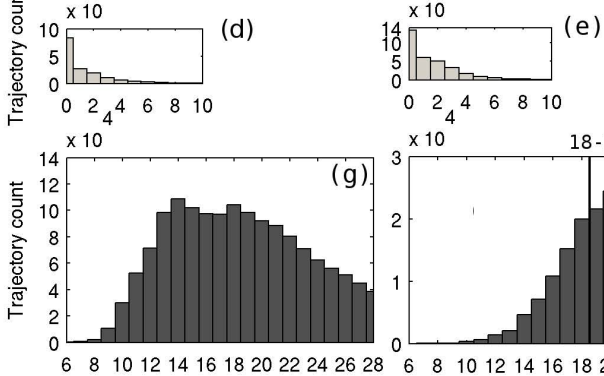

$\times 10 \quad 18-24$ days
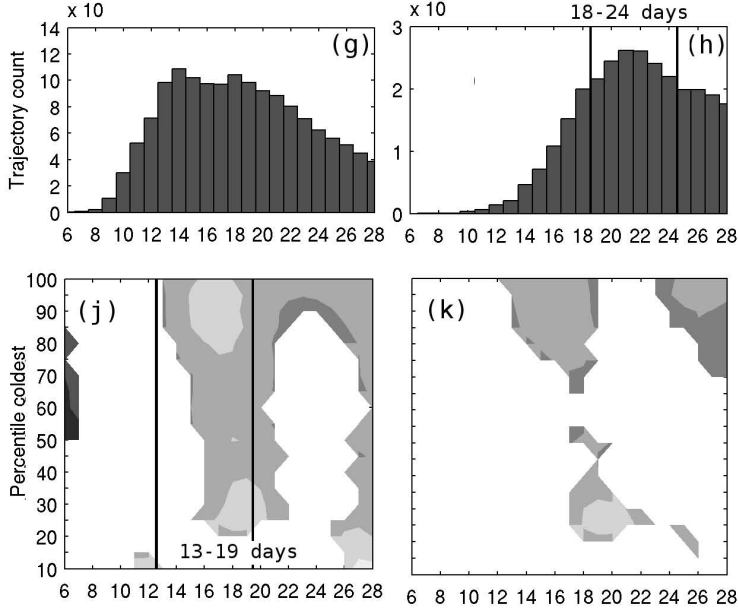

Days

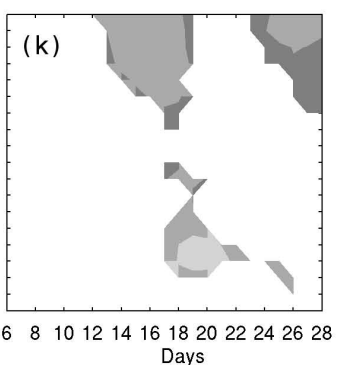

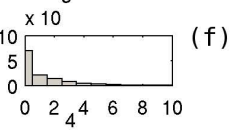
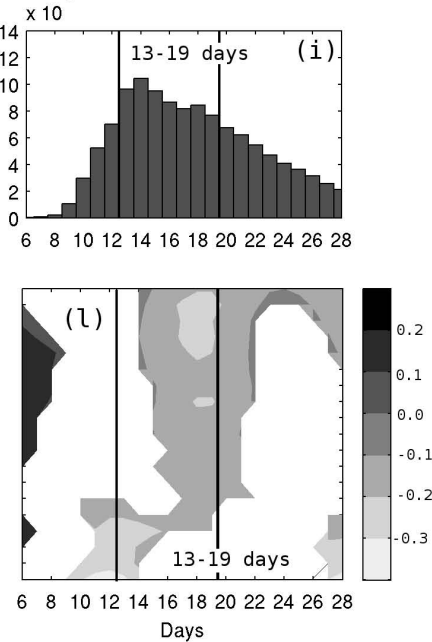

Fig. 3. (a-i) Trajectory times of air parcels for both West and East India domains (a, d, g), East India (b, e, h), West India (c, f, i). (a-c) Light bars show trajectory times from the domain to the evaporative region; dark bars show trajectory times from the domain to interior Australia. (d-f) Time spent by air parcels in Australia before leaving the continent. Parcels at the zero bin have not left Australia by the 30th day. (g-i) Trajectory times from the domain to when the air parcels leave Australia. (j-l) sections of Fig. 4 matched to the same time scale on the abscissa.

average residence time of moisture, it is possible for water vapour from the evaporative region to retained until West India. This answers the second caveat.

The distribution of trajectory times from India to interior Australia, as demarcated by the lower magenta line in Fig. 2 is shown as dark bars in Fig. 3a-c. West India air parcels take about 12-16 days to reach interior Australia, while East India air parcels take substantially longer, about 17-24 days. This further highlights that West India and East India air parcels are inherently different and should be analysed separately. Figure $3 \mathrm{~d}-\mathrm{f}$ show the distribution of time that air parcels spend inside Australia after passing the demarcated line in Australia. Parcels at the zero bin have not left Australia by the 30th day of the back-trajectory. About half of the air parcels are still in Australia at the 30th day, and the rest have left Australia. However, as trajectory calculation become increasingly inaccurate as integration time progresses, these distribution should be considered more qualitative than quantitative.

To obtain some kind of upper bound of time-lag between low temperature events in Australia and precipitation, the time taken to travel from the Indian end of the back-trajectory to the time when the air parcels leave Australia after having back-entered Australia from the Indian Ocean is used. For air parcels that remain in Australia up to the 30th day of the back-trajectory, low temperature events are assumed to occur at the time when these air parcels back-entered interior Australia (i.e. hit the demarcation line), to avoid inventing circulation times for them. The distribution of trajectories times is shown in Fig. 3g-i, with a time lag of about 13-19 days with the mode of 14 days.

\subsection{Satellite rainfall and reanalysis temperature}

Figure $4 \mathrm{a}-\mathrm{c}$ show the lag correlation between NNRP Australian temperature and TRMM rainfall for Entire India, East India and West India domains. The Indian monsoon rainfall is strongly auto-correlated at time lags of 10-20 days and 30-60 days, the dominant modes of its intraseasonal oscillations. Lag-correlations of Indian monsoon rainfall with any variable that produces a positive or negative correlation at any time-lag will produce mirrored positive or negative correlation 10-20 days and 30-60 days away. These correlations can only be rejected on the ground of physicality; the direction of large-scale circulation excludes correlations 

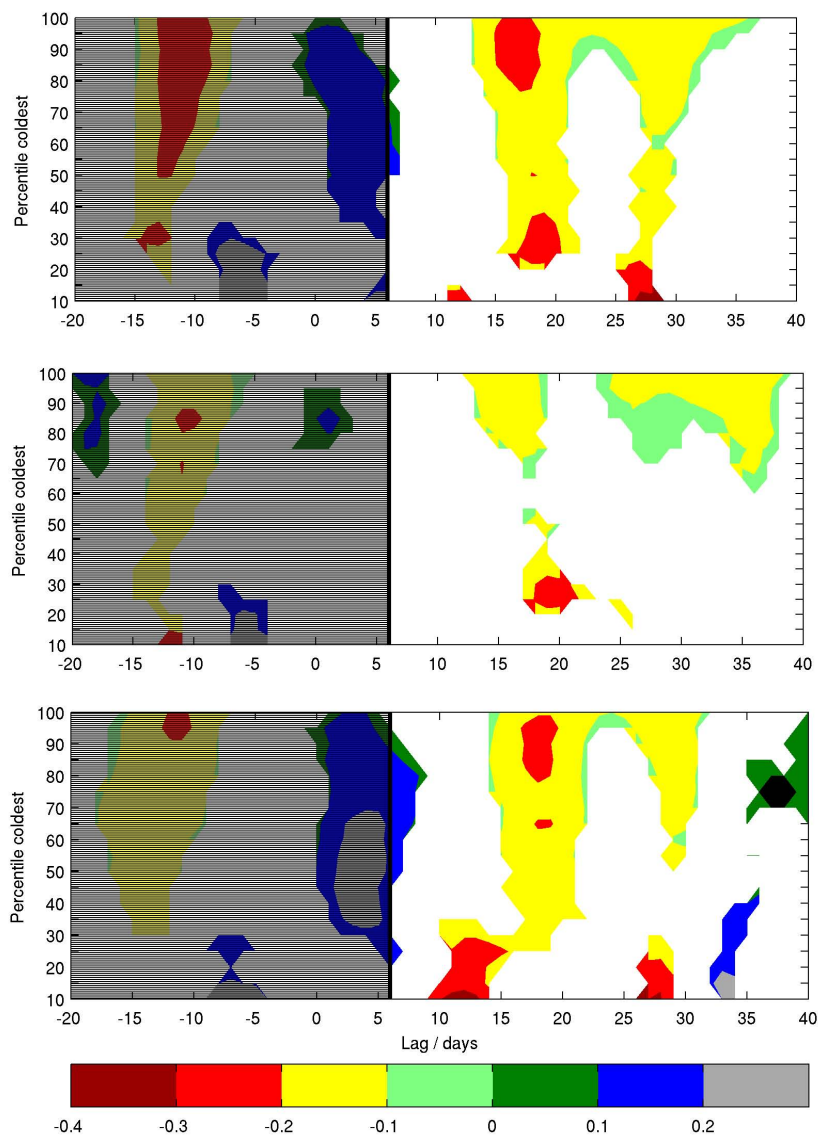

Fig. 4. (a) Lag correlation, significant at $95 \%$ confidence level, between Indian rainfall from TRMM and Australian temperature from NNRP for the Entire India domain. Shaded area shows unphysical time-lags. (b, c) Same as (a) but for the East India and West India domains respectively.

before when information can propagate from Australia to India (hatched regions of Fig. 4a-c). This leaves at most two correlation bands that are physical. Figure $3 \mathrm{j}-1$ show the correlation bands on the same abscissa scale as the backtrajectory time histograms from Sect. 4.1.

In Fig. $3 \mathrm{j}$ for the Entire India domain, a broad W-shaped anti-correlation trough can be seen for lags of more than 10 days. Both anti-correlation troughs while significant, are quite weak, with correlation coefficients between -0.10 and -0.30 . The left branch of the trough seems to correspond to the 13-19-day West India trajectories. The right branch may initially seem to correspond to the East India trajectories, but firstly it is occurs at a much later time than the timescale of travel from Australia to India (Fig. 3h), and secondly the timescale of travel precludes such a relation.

When the rainfall domain is restricted to East India (Fig. 3k), both troughs have almost disappeared. Some regions of anti-correlation still remain, indicating that East India trajectories of shorter travel times do contribute to the first anti-correlation trough in Fig. 3j. There may be regions in East India where the air parcels' travel time from Australia is short enough to still retain influence from their origin, but this does not make East India of sufficient interest for further study in this work.

When the rainfall domain is restricted to West India (Fig. 31), both troughs are retained. For the left trough, the anti-correlation between the cold temperatures and rainfall in the West India domain becomes more apparent. When warm temperatures are excluded leaving only the coldest 30th percentile, the strength of anti-correlation in the left branch increases to between -0.2 and -0.4 . It is clear that rainfall in the West India domain is responsible for both branches of the trough. Since the two troughs are 10-15 days apart, the second trough is likely to be due to autocorrelation of the rainfall from the 10-20 days mode.

For further discussion relevant to the hypothesis, which requires both realistic timescales and correlation between Indian rainfall and low inland Australia temperatures, we focus on West India.

\subsection{In-situ observations}

The location of the Indian rain gauges used for the correlation with VCD is plotted in Fig. 5. Magenta squares show gauges where the there is significant correlation between VCD and seasonal mean rainfall at $95 \%$ confidence level. The correlation values for these gauges are shown in Table 1.

6 out of 19 gauges in the West India domain individually show significant Australia-India teleconnection at $95 \%$ confidence level, and they lie in or near regions showing net precipitation. The region of net precipitation does not exactly match the set of stations demonstrating correlation between rain gauges and $\mathrm{VCD}$, but this may be due to the coarse spatial $\left(2.5^{\circ} \times 2.5^{\circ}\right)$ and temporal (6-hourly) resolution of the reanalysis winds used for the back-trajectory calculations which created some offset and mismatch of the net precipitation.

The contribution to net precipitation over the stations by air parcels originating from Australia forms only a small part of the total net precipitation. Therefore, correlation is not assured when any station receives net precipitation from air parcels originating from Australia. In order for the positive correlation to be seen, this contribution must be strong enough relative to contributions by air parcels from elsewhere, or its variations in Australian moisture will be completely dominated by variations of the other contributions. Nor does a significant correlation at any single station show that seasonal mean rainfall over West India as a domain is correlated with VCD, since significant correlations can arise by chance when a large number of stations are tested (see Wilks (1995) for a discussion). Therefore, the authors carry out a field correlation test, which tests whether the number of stations in West India showing positive correlation between gauge seasonal mean rainfall and VCD can arise by chance. 6 out of 19 gauges means significant field correlation between 
Table 1. Correlations between gauge rainfall and VCD.

\begin{tabular}{lrr}
\hline Name of station & Location $\left({ }^{\circ} \mathrm{E},{ }^{\circ} \mathrm{N}\right)$ & Correlation \\
\hline Goa/Panjim & $73.8,15.5$ & 0.84 \\
Kozhikode & $75.8,11.3$ & 0.78 \\
Hissar & $75.7,29.2$ & 0.74 \\
Kota Aerodrome & $75.9,25.2$ & 0.72 \\
Kakinada & $82.2,17.0$ & 0.72 \\
Cuddalore & $79.8,11.8$ & 0.67 \\
Bikaner & $73.3,28.0$ & 0.55 \\
Jaipur/Sanganer & $75.8,26.8$ & 0.55 \\
\hline
\end{tabular}

seasonal mean rainfall over West India and VCD at $95 \%$ confidence level (see Appendix B for details).

There is no significant field correlation between seasonal mean rainfall in the East India domain and VCD at $95 \%$ confidence level.

\subsection{Climatic indices}

ENSO and IOD are known to have impacts on Australia (Meyers et al., 2007) Therefore it is possible that the Australia-India teleconnection is part of these two tropical climatic patterns. Correlation of VCD separately with Nino3.4 (Fig. 6a), Nino4 (not shown) and DMI (Fig. 6b) does not yield significant results. The lack of relationship between VCD and ENSO or IOD shows that the teleconnection is not due to the coordinated impact of ENSO or IOD on Australia temperature and rainfall in the West Indian domain. This may be understood as ENSO and IOD are tropical patterns while VCD measures temperature over all of Australia inclusive of subtropical and mid-latitude regions.

\subsection{Possible mechanism}

The results of the previous sections are consistent with the proposed Australia-India teleconnection for which we propose the following mechanism: the advection of cold dry Australian air from southeast to northwest over the Indian Ocean where the enhanced evaporation rate ultimately feeds the enhanced rainfall rate downstream in West India.

As Australia lies mostly in the subtropics and is subjected to oceanic influences, winters in Australia are generally mild. But extreme lows in Australia winter temperature are commonly associated with subseasonal cold spells or "cold-air outbreaks", which are due to mid-latitude baroclinic wave activity. This is especially so since the stations from which VCD is computed are clustered in southeast Australia. Coldair outbreaks from 1972 to 1991 have been tabulated by Perrin and Simmonds (1995) and Simmonds and Richter (2000) using percentile temperature thresholds as criteria. They occurred in all five coldest years (i.e. the coldest quartile) ranked by VCD in this period: 1978, 1983, 1986, 1990, 1981 (in decreasing coldness). This suggests that cold-air out-

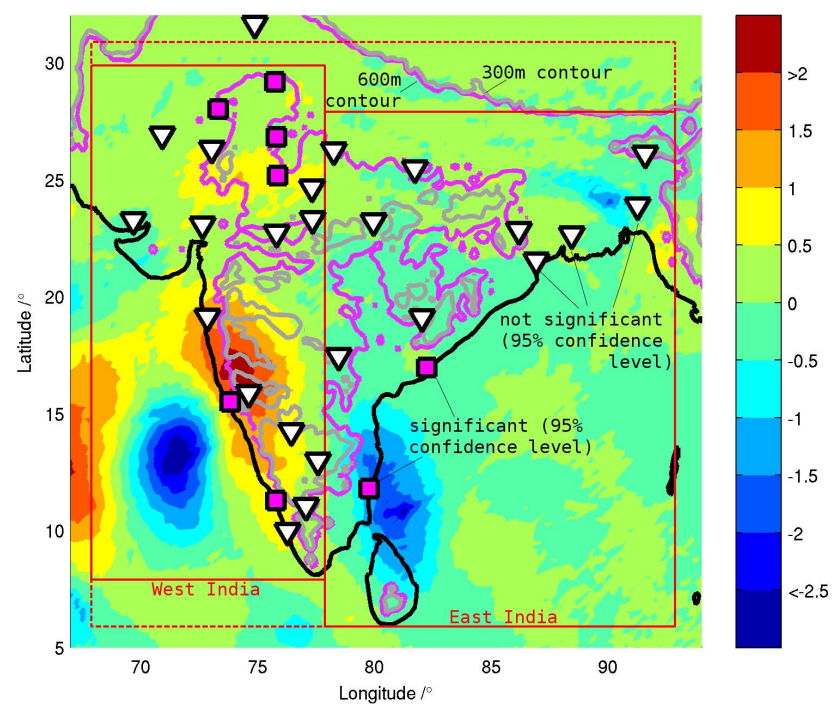

Fig. 5. Shading shows climatological accumulated net water vapour sink $\overline{p-e}$ ( $\mathrm{cm} /$ season) calculated from back-trajectories between India and Australia that precipitate first in the West India domain but in greater detail. The correlation between VCD and seasonal mean rainfall is calculated for rain gauges marked by squares and triangles. a)

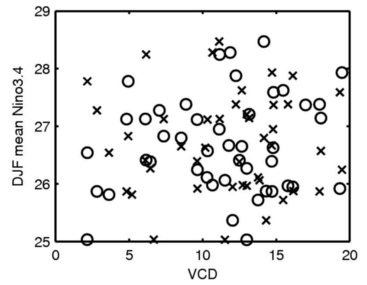

b)

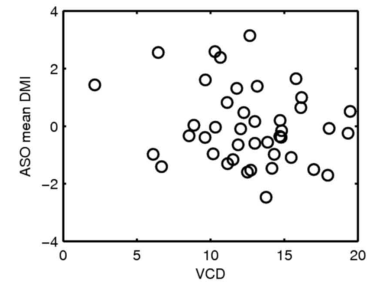

Fig. 6. Scatter plots of: (a) mean Nino3.4 in December-JanuaryFebruary (DJF) versus number of very cold days (VCD) in the same year (crosses) and the next year (circles) by the December month; (b) mean DMI in August-September-October versus VCD in the same year.

breaks in Australia is a likely cause of extreme low temperatures. How such low Australian temperature promote rainfall in West India is explored next.

Very low winter temperature implies that air over Australia has very low saturation vapour pressure, and hence very low specific humidity. This air warms up as it moves across Australia and over tropical Indian Ocean. We show below that evaporative fluxes calculated from observations and reanalysed dynamical variables are consistent with the picture of remote influence of cold-air outbreaks on Indian rainfall.

Figure 7a shows the composite pattern of enhanced evaporation in the five extreme years mentioned above, with three possible a priori causes: drier surface air, stronger surface wind, and/or warmer SST. The extent of the significant positive evaporation rate anomalies just west of Australia 

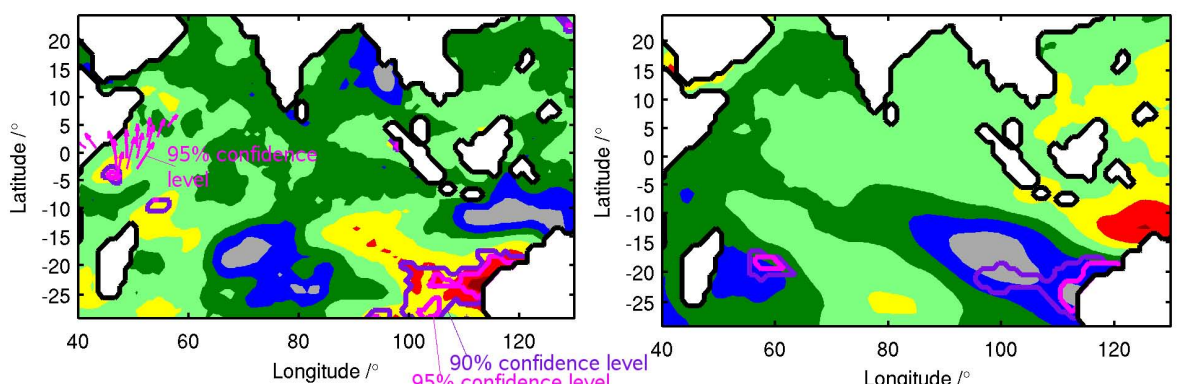

(a)
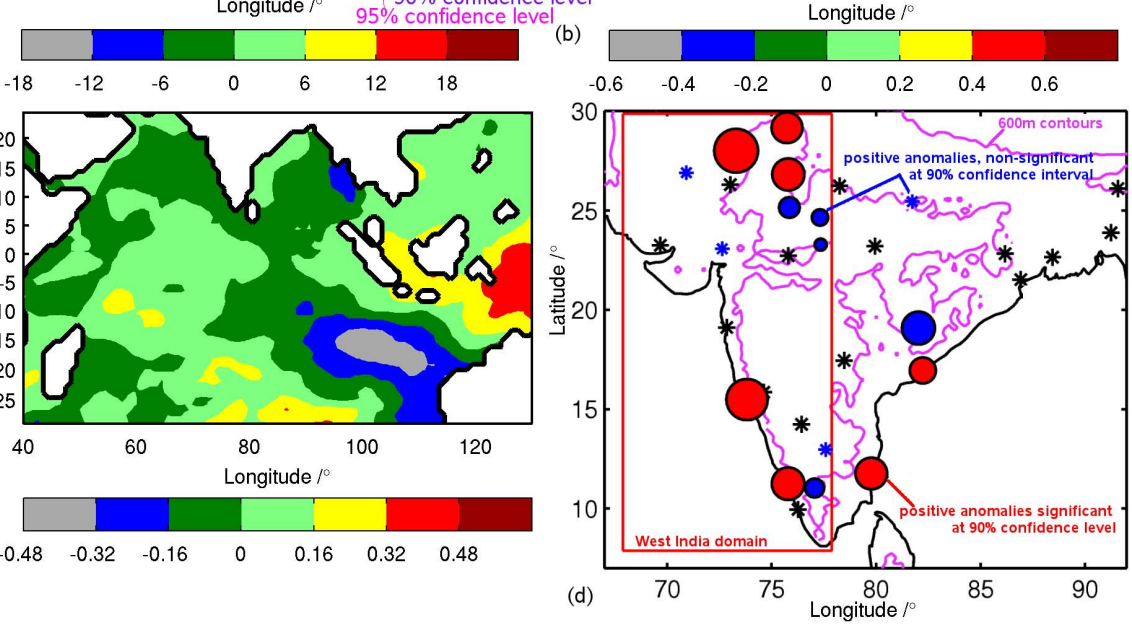

Fig. 7. (a) Composite for 1978, 1981, 1983, 1986, 1990 of anomalies of sea surface evaporation rate ( $\mathrm{cm} \mathrm{yr}^{-1}$, shaded), $10 \mathrm{~m}$-wind anomalies (arrows) (b) Same but for specific humidity at $2 \mathrm{~m}$ height $\left(\mathrm{g} \mathrm{kg}^{-1}\right)$. (c) Same but for SST (K). (d) Mean anomalies of seasonal mean daily rainfall for 1978, 1981, 1983, 1986, 1990, normalized to the climatological standard deviation, $s$, of each rain gauge. Radius of circles are proportional to the mean anomalies $(0.5-1.0 s)$. Where the circle becomes too small to be clearly visible $(<0.15 s)$, it is replaced with an blue asterisk. Black asterisks mark stations that do not have a positive anomaly.

corresponds to that of the significant negative specific humidity anomalies at $2 \mathrm{~m}$ height (Fig. $7 \mathrm{~b}$ ). The significant $10 \mathrm{~m}-$ wind anomalies (magenta arrows in Fig. 7a) lie offshore of East Africa but does not overlap with any significant anomalies of evaporation rate. The SST anomalies (Fig. 7c) overlapping with the region of significant enhanced evaporation are negative and so tend to retard evaporation rate, suggesting instead that cold SST anomalies may be the effect of enhanced evaporation rather than the cause. Thus, drier surface air and not surface wind perturbations or warm SST is the more likely reason for the enhanced evaporation rate. SST anomalies north of Australia are positive but while such SST anomalies have been noted to correlate with Indian monsoon rainfall by Nicholls (1995), they were employed as proxies for ENSO. In this case and consistent with the last section, neither the SST nor the surface wind anomalies closely resemble ENSO or IOD anomalies which affect evaporation, and the years in the composite are variously neutral, negative or positive in ENSO and IOD phases (cf. Meyers et al., 2007). The influence of ENSO, if any, would be indirect Nicholls (1989) pointed out that the anomalies in the SST north of Australia can also be a consequence of large-scale winter cloud bands that form when tropical air is pushed above intrusions of cold air from the mid-latitudes (Tapp and Barrell, 1984), and ENSO phases alter the frequency of such cloud band formations (Kuhnel, 1988). Indeed, the SST anomalies obtained here have a pattern that resembles that associate with the cloud bands, rather than ENSO.

We note that the transport of mid-latitude air to tropical regions leading to enhanced tropical rainfall is not unheard of. In the Northern Hemisphere, air mass over the Asian continent has been observed to be transported to northwest of Borneo (Chang et al., 1979) during boreal winter. These cold surges are a combination of cold-air outbreaks and the Asian winter monsoon flow, and result in increased low-level convergence which then enhances convection in southern South China Sea. The transport of mid-latitude air from Australia to eastern tropical Indian Ocean is the Southern Hemisphere's analogue of the Asian cold surge. The strength of the lowlevel monsoon circulation brings the mid-latitude influence further, resulting in a cross-equatorial impact on western India.

Figure $7 \mathrm{~d}$ shows the distribution of the rain gauges where the seasonal mean daily rainfall is anomalously high for the same five extreme years mentioned above. The distribution of rain gauges showing the Australia-India teleconnection in Fig. $1 \mathrm{~b}$ is also consistent with this understanding. 
Although the Australia-India teleconnection is demonstrated from in-situ observations on the interannual or longer timescale, this is due to VCD being a yearly statistic. Interannual patterns and long-term trends affect Australian temperature and the teleconnection mechanism does not differentiate between the reasons for unusually cold temperature. Nevertheless, even when the seasonal signature is removed as carried out in Sect. 4.2, sub-seasonal periods of low winter temperature in Australia can still promote sub-seasonal periods of rainfall in the West India domain.

\section{Conclusions}

A mechanism for a teleconnection between winter inland Australian temperature and monsoon rainfall in west India is proposed: when there is unusually low temperature over inland Australia during the austral winter, the dry air advecting northwestward out of a cold Australia enhances evaporation rate over eastern tropical Indian Ocean, and this enhances rainfall over two regions in West India after 13-19 days.

On a climatological basis, $3 \%$ of the air over West India originates from Australia, as demonstrated from the backtrajectories (Fig. 1b). The transport of water vapour from off the west coast of Australia to India is physically possible as the trajectory time between the evaporative region west of Australia and India is 8-13 days, which is consistent with the 10 day average residence time of water vapour in the atmosphere (Numaguti, 1999). The amount of air of Australian origin, as represented by the trajectories, passes over the ocean just west of Australia which constitutes a non-negligible source of water vapour for the Indian summer monsoon, and contributes to $0.5-1.5 \%$ of the climatological net precipitation over West India. This contribution is concentrated over two regions - the slopes of the Western Ghats and Northwest India (Fig. 5). Locally, the year-toyear net precipitation of Australian origin is highly variable, ranging from negligible contributions to $10 \mathrm{~cm} / \mathrm{JJA}$ season. As the Indian monsoonal rainfall is highly variable as well, case studies are recommended to determine the extent of any Australian influence.

Statistics are performed on satellite, in-situ and reanalysis data to determine if the influence by low inland Australian winter temperature on Indian summer monsoon rainfall can be detected. Statistically significant lagged correlation between NCEP temperature and TRMM rainfall over $11 \mathrm{yr}$ were found that demonstrate the correct time delay between cold temperature anomaly and rainfall enhancement within a season (Fig. 3a-1). Statistically significant field correlation (Wilks, 1995, also Appendix B for easy reference) was found to exist between VCD ("Very cold days", see Sect. 3.3 for definition) and gauge rainfall over a long time base ( $32 \mathrm{yr}$, Fig. 5). The local gauge correlations in Table 1 are comparable to those of operational predictors for total seasonal rainfall in India. E.g. Indian Ocean SST anomaly, North At- lantic SST anomaly and European land surface air temperature anomaly have correlations of $0.52,-0.45$ and 0.42 respectively (Rajeevan et al., 2007) with Indian rainfall. However, the caveat is that the relation is only locally useful for certain regions in West India.

The correlations described above are consistent with the proposed mechanism, but do not exclude the possibility of an external atmospheric variability that influences both Australian winter temperature as well as Indian monsoonal rainfall. The proposed influence is not directly linked to the dominant influences of Indian monsoon variability, the ENSO and the IOD, since correlation of VCD with Nino3.4, Nino4 and DMI does not yield significant results (Fig. 6). However, since Indian summer monsoon variability is influenced by many factors (see Introduction), testing with more indicators of atmospheric variability is recommended.

Australian winters are relatively mild, and extreme lows in Australia winter temperature are commonly associated with subseasonal cold spells or "cold-air outbreaks", which are due to mid-latitude baroclinic wave activity. The proposed mechanism may also be viewed as an example of how southern hemispheric mid-latitude weather can influence northern hemispheric monsoon rainfall. Figure $7 \mathrm{a}-\mathrm{c}$ show higher evaporation and drier air over the ocean just west of Australia during cold air outbreak years, which is consistent with the hypothesis that colder air travelling westwards from Australia results in drier air over the ocean just west of Australia and enhances evaporation. In addition, the SST west of Australia is anomalously cold during the outbreak years, excluding the other possibility of warmer SST enhancing evaporation. Unfortunately, there is a lack of direct horizontal water vapour flux observations to show enhanced transport from Australia to India in cold-air outbreak years, and reanalysis datasets are too much subjected to uncertainties in model parametrisation for tropical convective rainfall to show reliably or significantly the flux anomalies for composites of a few years. Finally, gauge rainfall is anomalously high in the outbreak years (Fig. 7d).

As the Australian contribution to total Indian precipitation is small, and such a mechanism only comes into play during episodes of low inland Australian temperature, the proposed mechanism in no way detracts from the dominant influence of ENSO and IOD on Indian monsoonal rainfall. However, while these important influences are well-known, it is shown to be physically possible and statistically consistent that some of the monsoonal rainfall variability may be influenced by conditions as far away as mid-latitude Australia. Further study is recommended through modelling and comparison with other known causes of atmospheric variability to confirm the existence of such a mechanism and determine the extent of its influence during specific low temperature episodes. 


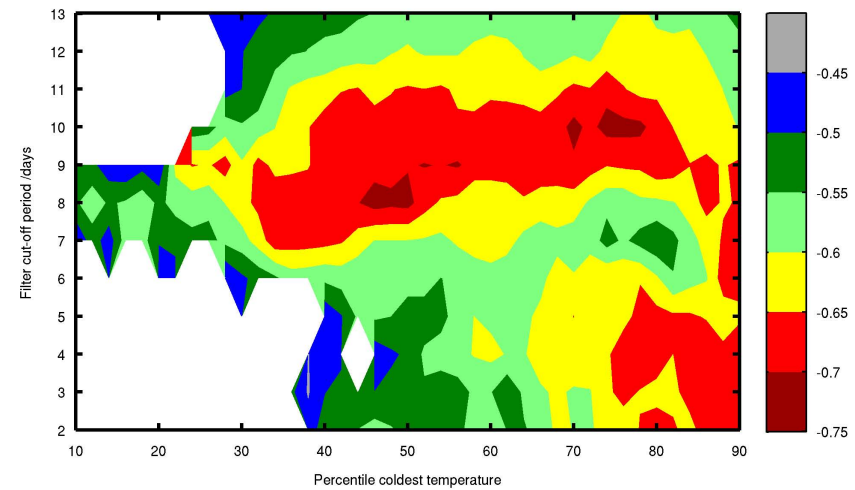

Fig. A1. Correlation coefficients between VCD and mean of temperatures below different percentile coldest temperatures after an $n$-day-to-2-month bandpass filter. Shaded regions are significant at $90 \%$ confidence level.

\section{Appendix A}

\section{VCD as a proxy}

It is reasoned dynamically in Sect. 3.3 that VCD is a proxy for extreme cold over Australia. Here we show that VCD is indeed related to the percentile mean temperatures in Australia calculated in Sect. 3.2.

Figure A1 shows the correlation coefficient between VCD and the percentile mean temperatures in Australia after applying an $n$-day-to-2-months bandpass filter to the temperature, using different $n$. Shaded regions are where the correlation coefficient is significantly non-zero at $90 \%$ confidence level. There is significant anti-correlation between VCD and the mean percentile temperature, about -0.5 to -0.6 , over a wide range of $n$ and temperature percentiles. The lack of significance for lower temperature percentiles with increasing $n$ is likely to be due to the reduced amplitude of temperature fluctuations after filtering. However, with less filtering the correlation suffers, as can be seen from the region of $n<7$ and sub-40 percentiles in Fig. A1.

It can be seen that VCD is indeed representative of low temperatures in Australia. Furthermore, while low temperatures as counted by VCD are affected by interannual fluctuations in the amplitude of the seasonal cycle, even with seasonal signals removed the sub-seasonal signals have a significant effect on temperatures.

\section{Appendix B}

\section{Field significance}

Significance testing repeated at a large number of local points (in this case, rain gauges) will inevitably yield false positives by chance. Field significance tests whether the positives obtained in the entire set of points arise from chance.
Following Livezey and Chen (1983) and Wilks (1995), we wish to know what is the minimum number of gauges needed out of the 19 gauges in West India, to be certain the positive results did not come about by chance, at $\alpha=0.05$ (i.e. $95 \%$ confidence level).

$$
\begin{aligned}
& \text { Probability }(0 \text { of } 19)={ }^{19} C_{0}(0.95){ }^{19}=0.34 \\
& \text { Probability }(1 \text { of } 19)={ }^{19} C_{1}(0.95){ }^{18}(0.05)=0.38 \\
& \text { Probability }(2 \text { of 19) }=0.18 \\
& \text { Probability }(3 \text { of 19) }=0.05 \\
& \text { Probability }(\text { more than } 3 \text { of } 19)=0.05
\end{aligned}
$$

Therefore, it is required that more than 3 gauges out of 19 gauges in west India test positive to demonstrate a significant relationship at confidence level $95 \%$.

Acknowledgements. We would like to thank: BOM, JAMSTEC, NASA/JAXA, NCEP/NCAR, NOAA and WHOI for use of their datasets; I. Simmonds and K. Keay for the trajectory code; and C. K. Teo for extracting the TRMM data; the anonymous reviewers for their comments.

Edited by: A. Stohl

\section{References}

Annamalai, H., Slingo, J., Sperber, K., and Hodges, K.: The mean evolution and variability of the Asian summer monsoon: Comparison of ECMWF and NCEP-NCAR reanalyses, Mon. Weather Rev., 127, 1157-1186, 1999.

Barras, V. and Simmonds, I.: Observation and modelling of stable water isotopes as diagnostics of rainfall dynamics over southeastern Australia, J. Geophys. Res., 114, D23308, doi:10.1029/2009JD012132, 2009.

Chang, C., Erickson, J., and Lau, K.: Northeasterly cold surges and near-equatorial disturbances over the winter MONEX area during December 1974 .1. Synoptic aspects, Mon. Weather Rev., 107, 812-829, 1979.

Clark, C., Cole, J., and Webster, P.: Indian Ocean SST and Indian summer rainfall: Predictive relationships and their decadal variability, J. Climate, 13, 2503-2519, 2000.

Clarke, R., Dyer, A. J., Brook, R. R., Reid, D. C., and Troup, A. J.: The Wangara Experiment: Boundary Layer Data, Tech. Paper No. 19, Div. Met. Phys., CSIRO, Australia, 1971.

Gimeno, L., Drumond, A., Nieto, R., Trigo, R. M., and Stohl, A.: On the origin of continental precipitation, Geophys. Res. Lett., 37, L13804, doi:10.1029/2010GL043712, 2010.

Goswami, B. and Mohan, R.: Intraseasonal oscillations and interannual variability of the Indian summer monsoon, J. Climate, 14, 1180-1198, 2001.

Gregory, S.: Interrelationships between Indian and Northern Australian summer monsoon rainfall values, Int. J. Climatol., 11, 5562, 1991.

Hahn, D. and Shukla, J.: Apparent relationship between Eurasian snow cover and Indian monsoon rainfall, J. Atmos. Sci., 33, 2461-2462, 1976.

Hanley, D., Bourassa, M., O'Brien, J., Smith, S., and Spade, E.: A quantitative evaluation of ENSO indices, J. Climate, 16, 12491258, 2003. 
Hung, C., Liu, X., and Yanai, M.: Symmetry and Asymmetry of the Asian and Australian Summer Monsoons, J. Climate, 17, 2413 2426, 2004.

IMD: Indian Meteorological Department, http://www.imd.gov.in/ section/, last access: 2012.

Joseph, P., Liebmann, B., and Hendon, H.: Interannual variability of the Australian summer monsoon onset - possible influence of Indian-summer monsoon and El-Nino, J. Climate, 4, 529-538, 1991.

Kalnay, E., Kanamitsu, M., Kistler, R., Collins, W., Deaven, D., Gandin, L., Iredell, M., Saha, S., White, G., Woollen, J., Zhu, Y., Chelliah, M., Ebisuzaki, W., Higgins, W., Janowiak, J., Mo, K. C., Ropelewski, C., Wang, J., Leetmaa, A., Reynolds, R., Jenne, R., and Joseph, D.: The NCEP/NCAR 40-year reanalysis project, B. Am. Meteor. Soc., 77, 437-471, 1996.

Kripalani, R. and Kulkarni, A.: Climatology and variability of historical Soviet snow depth data: some new perspectives in snow - Indian monsoon teleconnections, Clim. Dynam., 15, 475-489, 1999.

Krishnamurthy, V. and Shukla, J.: Intraseasonal and interannual variability of rainfall over India, J. Climate, 13, 4366-4377, 2000.

Krishnamurti, T., Han, S., and Misra, V.: Prediction of the dry and wet spell of the Australian monsoon, Int. J. Climatol., 15, 753$771,1995$.

Kuhnel, I.: Tropical-extratropical cloudband climatology based on satellite data, Int. J. Climatol., 9, 441-463, 1988.

Lawrence, D. and Webster, P.: Interannual variations of the intraseasonal oscillation in the south Asian summer monsoon region, J. Climate, 14, 2910-2922, 2001.

Liu, X. and Yanai, M.: Influence of Eurasian spring snow cover on Asian summer rainfall, Int. J. Climatol., 22, 1075-1089, 2002.

Livezey, R. and Chen, W.: Statistical field significance and its determination by Monte Carlo techniques, Mon. Weather Rev., 111, 46-59, 1983.

Matsumoto, J.: The seasonal-changes in Asian and Australian monsoon regions, J. Meteor. Soc. Japan, 70, 257-273, 1992.

Meehl, G.: The annual cycle and interannual variability in the tropical Pacific and Indian-ocean regions, Mon. Weather Rev., 115, 27-50, 1987.

Meehl, G.: The south Asian monsoon and the tropospheric biennial oscillation, J. Climate, 10, 1921-1943, 1997.

Meyers, G., McIntosh, P., Pigot, L., and Pook, M.: The years of El Nino, La Nina, and interactions with the tropical Indian ocean, J. Climate, 20, 2872-2880, 2007.

Nicholls, N.: Sea surface temperatures and Australian winter rainfall, J. Climate, 2, 965-973, 1989.

Nicholls, N.: All-India summer monsoon rainfall and sea-surface temperatures around Northern Australia and Indonesia, J. Climate, 8, 1463-1467, 1995.

NNRP: NCEP Reanalysis data provided by the NOAA/OAR/ESRL PSD, Boulder, Colorado, USA, from their Web site: http://www. esrl.noaa.gov/psd/, last access: 2012.

Numaguti, A.: Origin and recycling processes of precipitating water over the Eurasian Continent: experiments using an atmospheric general circulation model, J. Geophys. Res., 104, 1957-1972, 1999.
OAFlux: Woods Hole Oceanographic Institution OAFlux Project, http://oaflux.whoi.edu/, last access: 2012.

Parthasarathy, B. and Mooley, D.: Some features of a long homogeneous series of Indian summer monsoon rainfall, Mon. Weather Rev., 106, 771-781, 1978.

Perrin, G. and Simmonds, I.: The origin and characteristics of coldair outbreaks over Melbourne, Aust. Meteo. Mag., 44, 41-59, 1995.

Rajeevan, M., Pai, D. S., Kumar, R. A., and Lal, B.: New statistical models for long-range forecasting of southwest monsoon rainfall over India, Clim. Dynam., 28, 813-828, 2007.

Rasmusson, E. and Carpenter, T.: The relationship between eastern equatorial Pacific sea-surface temperatures and rainfall over India and Sri-Lanka, Mon. Weather Rev., 111, 517-528, 1983.

Saji, N., Goswami, B., Vinayachandran, P., and Yamagata, T.: A dipole mode in the tropical Indian Ocean, Nature, 401, 360-363, 1999.

Simmonds, I. and Richter, T.: Synoptic comparison of cold events in winter and summer in Melbourne and Perth, Theor. Appl. Climatol., 67, 19-32, 2000.

Simpson, J., Kummerow, C., Tao, W., and Adler, R.: On the tropical rainfall measuring mission (TRMM), Meteorol. Atmos. Phys., 60, 19-36, doi:10.1007/BF01029783, 1996.

Singh, S., Kripalani, R., and Sikka, D.: Interannual variability of the Madden-Julian oscillations in Indian-summer monsoon rainfall, J. Climate, 5, 973-978, 1992.

Sodemann, H., Schwierz, C., and Wernli, H.: Interannual variability of Greenland winter precipitation sources: Lagrangian moisture diagnostic and North Atlantic Oscillation influence, J. Geophys. Res.-Atmos., 113, D03107, doi:10.1029/2007JD008503, 2008.

Sperber, K., Slingo, J., and Annamalai, H.: Predictability and the relationship between subseasonal and interannual variability during the Asian summer monsoon, Q. J. Roy. Meteor. Soc., 126, 2545-2574, 2000.

Stohl, A. and James, P.: A Lagrangian analysis of the atmospheric branch of the global water cycle. Part I: Method Description, Validation, and Demonstration for the August 2002 Flooding in Central Europe, J. Hydrometeorol., 5, 656-678, 2004.

Stohl, A. and James, P.: A Lagrangian analysis of the atmospheric branch of the global water cycle. Part II: Moisture transports between earth's ocean basins and river catchments, J. Hydrometeorol., 6, 961-984, 2005.

Tapp, R. and Barrell, S.: The North-west Australian cloud band, J. Climatol., 4, 411-424, 1984.

TRMM: Download source at GSFC, NASA, http://trmm.gsfc.nasa. gov/3b42.html, last access: 2012.

Troen, I. and Mahrt, L.: A simple-model of the atmospheric boundary-layer - sensitibity to surface evaporation, Bound.-Lay. Meteorol., 37, 129-148, 1986.

VCD: Australian Bureau of Meteorology, http://www.bom.gov.au/ climate/change/, last access: 2012.

Wilks, D.: Statistical methods in atmospheric sciences, Academic Press: San Diego, 1995.

Yu, L., Jin, X., and Weller, R.: Annual, seasonal, and interannual variability of air-sea heat fluxes in the Indian Ocean, J. Climate, 20, 3190-3209, 2007. 